\title{
Conf- $9408168--2$
}

PNL-SA-24027

\section{THE SOLUBILITY OF $\mathrm{Cr}(\mathrm{OH})_{3}(\mathrm{am})$ IN CONCENTRATED NaOH AND NaOH-NaNO SOLUTIONS $^{2}$}
A. R. Felmy
D. Rai
R. W. Fulton

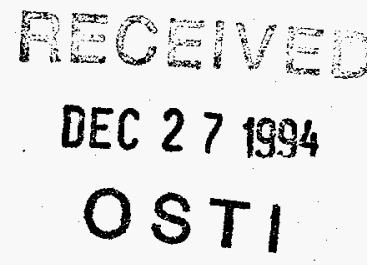

August 1994

Presented at the

Symposium of Scientific Issues Related to Safety and Treatment of Hanford Waste Conference

August 21-26, 1994

Washington, D.C.

Prepared for

the U.S. Department of Energy

under Contract DE-AC06-76RLO 1830

\author{
Pacific Northwest Laboratory \\ Richland, Washington 99352
}

\section{DISCLAIMER}

\begin{abstract}
This report was prepared as an account of work sponsored by an agency of the United States Government. Neither the United States Government nor any agency thereof, nor any of their employees, makes any warranty, express or implied, or assumes any legal liability or responsibility for the accuracy, completeness, or usefulness of any information, apparatus, product, or process disclosed, or represents that its use would not infringe privately owned rights. Reference herein to any specific commercial product, process, or service by trade name, trademark, manufacturer, or otherwise does not necessarily constitute or imply its endorsement, recommendation, or favoring by the United States Government or any agency thereof. The views and opinions of authors expressed herein do not necessarily state or reflect those of the United States Government or any agency thereof.
\end{abstract}




\section{DISCLAIMER}

Portions of this document may be illegible in electronic image products. Images are produced from the best available original document. 


\title{
The Solubility of $\mathrm{Cr}(\mathrm{OH})_{3}(\mathrm{am})$ in Concentrated $\mathrm{NaOH}$ and $\mathrm{NaOH}-\mathrm{NaNO}_{3}$ Solutions
}

\author{
Andrew R. Felmy \\ Dhanpat Rai \\ Robert W. Fuiton \\ Pacific Northwest Laboratory $y^{(a)}$ \\ Richland, WA 99352
}

\begin{abstract}
The solubility of $\mathrm{Cr}(\mathrm{OH})_{3}(\mathrm{am})$ was measured in concentrated $\mathrm{NaOH}$ ranging in concentration from $0.1 \mathrm{M}$ to $6.0 \mathrm{M}$ and in $\mathrm{NaOH}-\mathrm{NaNO}_{3}$ solutions with fixed $\mathrm{NaOH}$ concentration and variable $\mathrm{NaNO}_{3}$ concentration at room temperature $\left(22-23^{\circ} \mathrm{C}\right)$. Equilibrium between solids and solutions was approached relatively slowly and required approximately 60-70 days before steady-state concentrations were reached. A thermodynamic model, based upon the Pitzer equations, was developed from the solubility data in $\mathrm{NaOH}$, which includes only two aqueous $\mathrm{Cr}$ species $\left(\mathrm{Cr}(\mathrm{OH})_{4}^{-}\right.$and $\left.\mathrm{NaCr}(\mathrm{OH})_{4}(\mathrm{aq})\right)$ and ion-interaction parameters for $\mathrm{Na}^{+}$with $\mathrm{Cr}(\mathrm{OH})_{4}^{-}$. This model was then tested in the mixed $\mathrm{NaOH}-\mathrm{NaNO}_{3}$ solutions and found to be reliable.
\end{abstract}

(a) Pacific Northwest Laboratory is operated for the U.S. Department of Energy by Battelle Memorial Institute Under Contract DE-AC06-76RLO 1830. 


\section{Introduction}

Chromium is a major component of the Hanford waste tank sludges, and the presence of $\mathrm{Cr}$ in the sludges is a significant concern in the disposal of these sludges because $\mathrm{Cr}$ can interfere with the formation of waste glasses. It is, therefore, of interest to develop methodologies for removing $\mathrm{Cr}$ from the tanks sludges before these sludges are solidified into glass. One of the current pretreatment strategies for removing constituents that can interfere with glass formation, such as $\mathrm{P}$ and $\mathrm{Cr}$, is to wash/dissolve the sludges in basic $\mathrm{NaOH}$ solutions. It is, therefore, of interest to examine the solubility of likely Cr-containing precipitates in $\mathrm{NaOH}$ solutions. The $\mathrm{NaOH}$ wash solutions can also dissolve other constituents from the sludge, such as $\mathrm{NaNO}_{3}$, and since these constituents can reach high concentration, their effects, on the solubility of $\mathrm{Cr}$ compounds should also be examined. For these reasons the solubility of $\mathrm{Cr}$ precipitates was measured in both $\mathrm{NaOH}$ and $\mathrm{NaOH}$ $\mathrm{NaNO}_{3}$ solutions.

This study focused on the solubility of $\mathrm{Cr}(\mathrm{III})$ precipitates, rather than $\mathrm{Cr}(\mathrm{VI})$ phases, for three reasons. One, $\mathrm{Cr}(\mathrm{II})$ is stable over a wide range of $\mathrm{pH}$ and $\mathrm{Eh}$ conditions in aqueous solution (see Figure 1)... Two, the presence of reduced nitrogen compounds, such as $\mathrm{NO}_{2}{ }^{-}$, can enhance the stability of $\mathrm{Cr}(\mathrm{III})$ species over $\mathrm{Cr}(\mathrm{VI})$ species, and three, most $\mathrm{Cr}(\mathrm{VI})$ solid phases are very soluble and are unlikely to limit the solubility of $\mathrm{Cr}$ in the tank sludges. In addition, to the best of our knowledge, there are no existing data in the literature on the solubility of $\mathrm{Cr}(\mathrm{II})$ precipitates in mixed $\mathrm{NaOH}-\mathrm{NaNO}_{3}$ solutions and only limited data in $\mathrm{NaOH}$ solutions.

\section{Experimental Procedures}

The experimental procedures utilized in this study followed as closely as possible the procedure of Rai et al. (1987) who examined the solubility of $\mathrm{Cr}(\mathrm{OH})_{3}(\mathrm{am})$ in dilute sodium perchlorate solutions. All experiments were conducted in a controlled atmosphere chamber (99.99\% $\mathrm{N}_{2}$ with a few $\mathrm{ppm} \mathrm{O}_{2}$ ) at room temperature $\left(22-23^{\circ} \mathrm{C}\right)$. A $1 \mathrm{M} \mathrm{Cr}(\mathrm{III})$ stock solution was prepared from reagent grade $\mathrm{Cr}\left(\mathrm{NO}_{3}\right)_{3} \cdot 9 \mathrm{H}_{2} \mathrm{O}$ in acidic $0.1 \mathrm{M} \mathrm{HNO}$ to remove any traces of carbonate from the solution. Approximately $4 \mathrm{ml}$ of the $\mathrm{Cr}$ stock solution, 


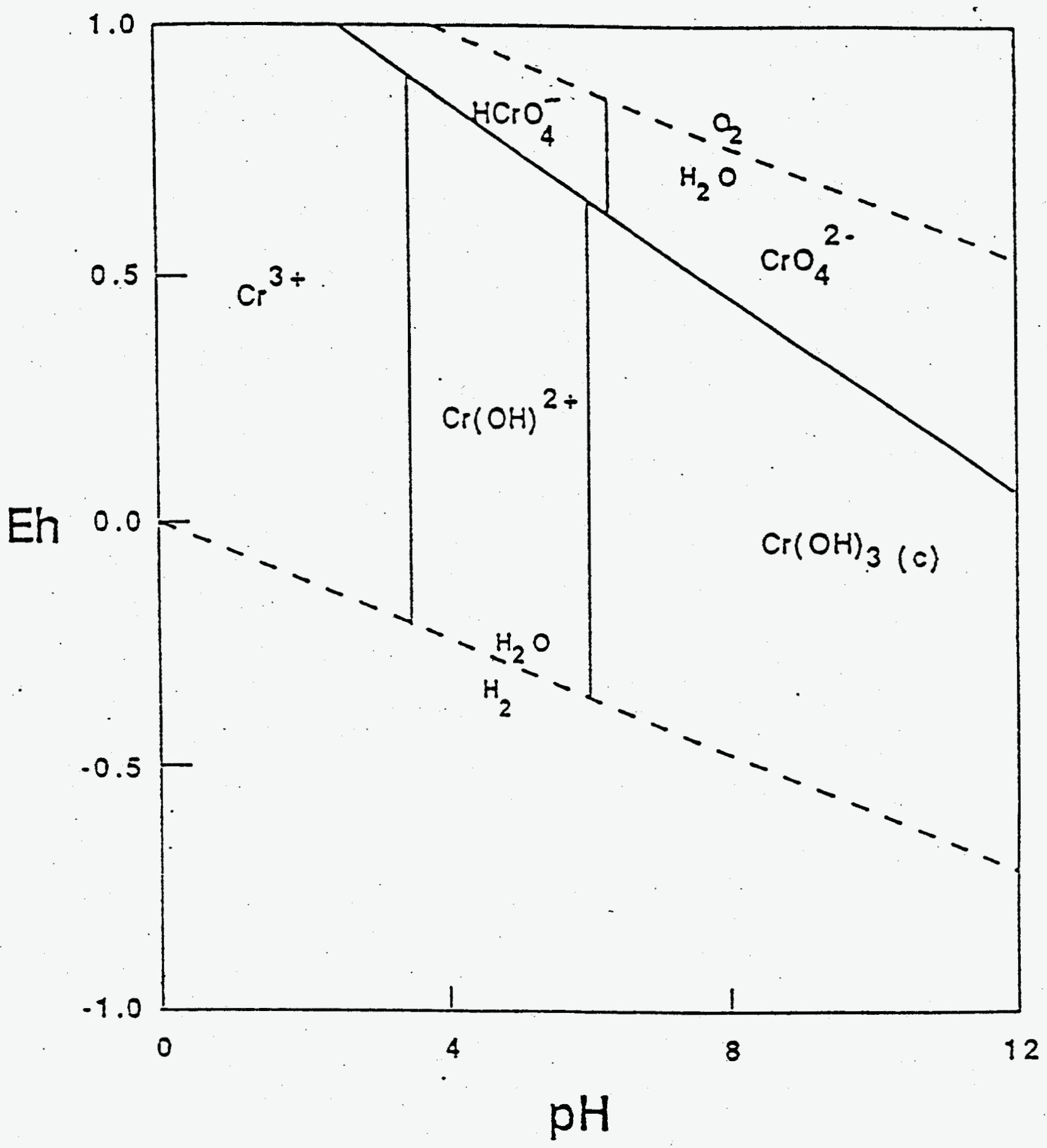

Figure 1. Eh-pH diagram representing stability fields for $\mathrm{Cr}(\mathrm{III})$ and $\mathrm{Cr}(\mathrm{VI})$ species at $25^{\circ} \mathrm{C}$ (WHC 1993). Boundaries are displayed for log activities of dissolved species $=-$ 6. Precipitated $\mathrm{Cr}(\mathrm{II})$ is represented as $\mathrm{Cr}(\mathrm{OH})_{3}(\mathrm{c})$. 
containing approximately $208 \mathrm{mg} \mathrm{Cr}$, were added to separate polyethylene centrifuge tubes and diluted to $10 \mathrm{ml}$ with deionized water that had been sparged with $\mathrm{N}_{2}(\mathrm{~g})$ to remove any trace of $\mathrm{CO}_{2}$. $\mathrm{Cr}(\mathrm{OH})_{3}(\mathrm{am})$ was precipitated by adjusting the $\mathrm{pH}$ of the solution in each centrifuge tube to approximately 9.5 with $\mathrm{CO}_{2}$ free $\mathrm{NaOH}$. The precipitate was allowed to age overnight in the mother liquor. The next day the precipitate was washed three times with deionized water that had been adjusted to $\mathrm{pH} 9.5$ to remove any residual $\mathrm{NO}_{3 .}$. Following washing, the precipitates were suspended in $35 \mathrm{ml}$ of the $\mathrm{NaOH}$ or $\mathrm{NaOH}+\mathrm{NaNO}_{3}$ solution of the appropriate molarity and placed on a shaker and continuously agitated.

The $\mathrm{NaOH}$ suspensions were sampled after 45 and 73 days of equilibration in the $\mathrm{NaOH}-\mathrm{NaNO}_{3}$ suspensions and were sampled after 24, 39, and 135 days of equilibration in the $\mathrm{NaOH}$ solutions. Sampling consisted of centrifugation followed by filtration through Amicon Type F-25 Centriflo Membrane Cones. Rai et al. (1987) describes the filtration procedure in detail and presents data demonstrating the effectiveness of these filters in separating solids from solutions in the case of dissolved $\mathrm{Cr}$ species. The resulting filtrate was then acidified to prevent the precipitation of $\mathrm{Cr}(\mathrm{OH})_{3}(\mathrm{am})$ and the dissolved $\mathrm{Cr}$ concentration determined by inductively coupled plasma emission spectroscopy (ICP) or inductively coupled plasma mass spectrometry (ICP-MS).

$\mathrm{X}$-Ray Diffraction (XRD) analysis was performed on selected $\mathrm{Cr}$ precipitates following the final sampling period. All precipitates were found to be amorphous to X-Ray. As a result, the solubility data reported in this study refer to the equilibrium solid phase as $\mathrm{Cr}(\mathrm{OH})_{3}(\mathrm{am})$.

\section{Results and Discussion}

The solubility data for $\mathrm{Cr}(\mathrm{OH})_{3}(\mathrm{am})$ in $\mathrm{NaOH}$ solutions in Figure 2a shows the same trend as the earlier results of Rai et al. (1987); Figure 2b, shows initially high solubilities that decrease with time. Equilibrium, or at least steady-state conditions, appear to be reached after approximately 60 days of equilibration. The solubilities in $\mathrm{NaOH}$ (Figure 2a) also show a consistent trend of increasing solubility with increasing $\mathrm{NaOH}$ concentration 

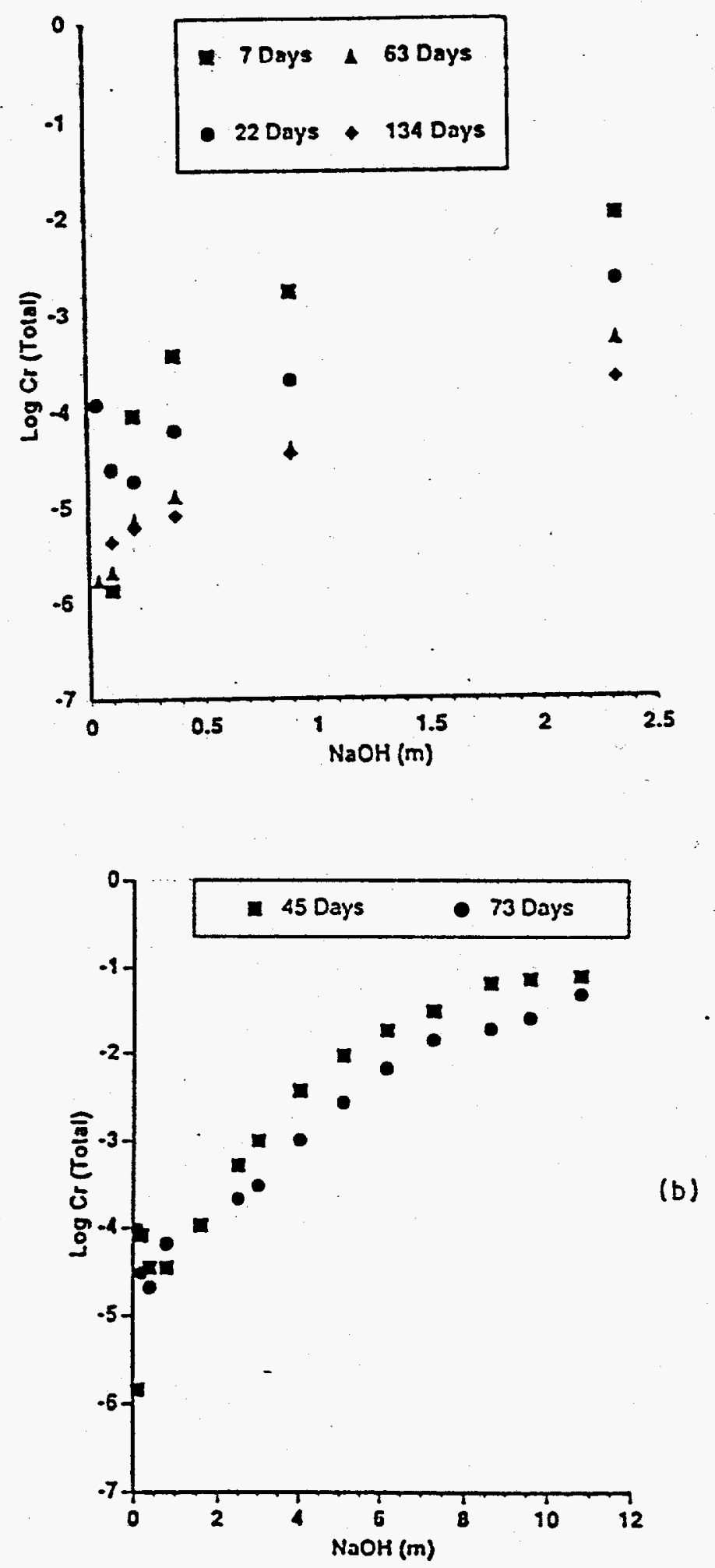

Figure 2. Solubility data for $\mathrm{Cr}(\mathrm{OH})_{3}(\mathrm{am})$ in $\mathrm{NaOH}$ solutions. (a) Data of Rai et al. 1987. (b) Data obtained in this study. 
even to approximately $10 \mathrm{~m} \mathrm{NaOH}$. This result is important in that it indicates that significant amounts of $\mathrm{Cr}(\mathrm{III})$ can be solubilized at high $\mathrm{NaOH}$ concentration. The solubilities obtained in this study, at least below $2.0 \mathrm{M} \mathrm{NaOH}$, are also in good agreement with those of Rai et al. (1987), see. Figure 3.

Rai et al. 1987 in their earlier work in dilute perchlorate media interpreted their results at $\mathrm{pH}$ values $>12$ in terms of only one solubility reaction:

$$
\text { (1) } \mathrm{Cr}(\mathrm{OH})_{3}(\mathrm{am})+\mathrm{OH}^{-}=\mathrm{Cr}(\mathrm{OH})_{4}^{-} \quad \log \mathrm{K}^{0}=-18.30
$$

Because these data were in relatively dilute solution, the calculated standard state equilibrium constant for this reaction should be reasonable. However, it is not expected that their model would be valid at high $\mathrm{NaOH}$ concentration owing to the large variation in the activity coefficients for $\mathrm{OH}^{-}$and $\mathrm{Cr}(\mathrm{OH})_{4}^{-}$. At high concentration, activity coefficients are not universal functions of ionic strength and this fact is accounted for in the Pitzer formalism by the use of ion-interaction coefficients for binary (i.e., $B^{0}, B^{1}, C^{\phi}$ for $\mathrm{Na}^{+}-\mathrm{OH}^{-}$and $\mathrm{Na}^{+}-$ $\mathrm{Cr}(\mathrm{OH})_{4}^{-}$) and common-ion ternary interactions (i.e $\theta$ for $\left.\mathrm{OH}^{-}-\mathrm{Cr}(\mathrm{OH})_{4}\right)^{-}$. Although the necessary Pitzer ion-interaction parameters for $\mathrm{Na}^{+}-\mathrm{OH}^{-}$are well known, the parameters involving the $\mathrm{Cr}(\mathrm{OH})_{4}$ ion are unknown and must be either calculated (fit) or estimated. As an example, if the equilibrium reaction (eqn 1) given by Rai et al. (1987) is combined with the Pitzer ion-interaction parameters for $\mathrm{Na}^{+}-\mathrm{OH}^{-}$given by Pabalan and Pitzer (1987) and the values for the $\mathrm{Al}(\mathrm{OH})_{4}^{-}$ion (Wesolowski 1992) are used as analogs for $\mathrm{Cr}(\mathrm{OH})_{4}^{-}$, the predicted solubilities (see dashed line in Figure 3) give very good agreement with the experimental data at low $\mathrm{NaOH}(<2 \mathrm{M})$ but are significantly below the experimental values at higher $\mathrm{NaOH}$ concentration. Several attempts to explain these deviations between model and experiment were tested. First, the values of $\mathrm{B}^{0}, \mathrm{~B}^{1}, \mathrm{C}^{\phi}$ for $\mathrm{Na}^{+}-\mathrm{Cr}(\mathrm{OH})_{4}^{-}$were fit to the $\mathrm{Cr}(\mathrm{OH})_{3}(\mathrm{am})$ solubility data in $\mathrm{NaOH}$. The resulting parameter values were all negative, a fact that can be indicative of ion association in the aqueous solution. However, when higher hydrolysis species such as $\mathrm{Cr}(\mathrm{OH})_{5}{ }^{2-}$, and $\mathrm{Cr}(\mathrm{OH})_{6}{ }^{3-}$ were introduced into the model and their standard chemical potentials fit to the data in $\mathrm{NaOH}$, the resulting model did not work well when tested on the $\mathrm{Cr}(\mathrm{OH})_{3}(\mathrm{am})$ solubility data in mixed $\mathrm{NaOH}-\mathrm{NaNO}_{3}$ solutions. In addition, there are no data in the JCPDS for $\mathrm{Cr}(\mathrm{III})$ solid phases of higher sodium content 


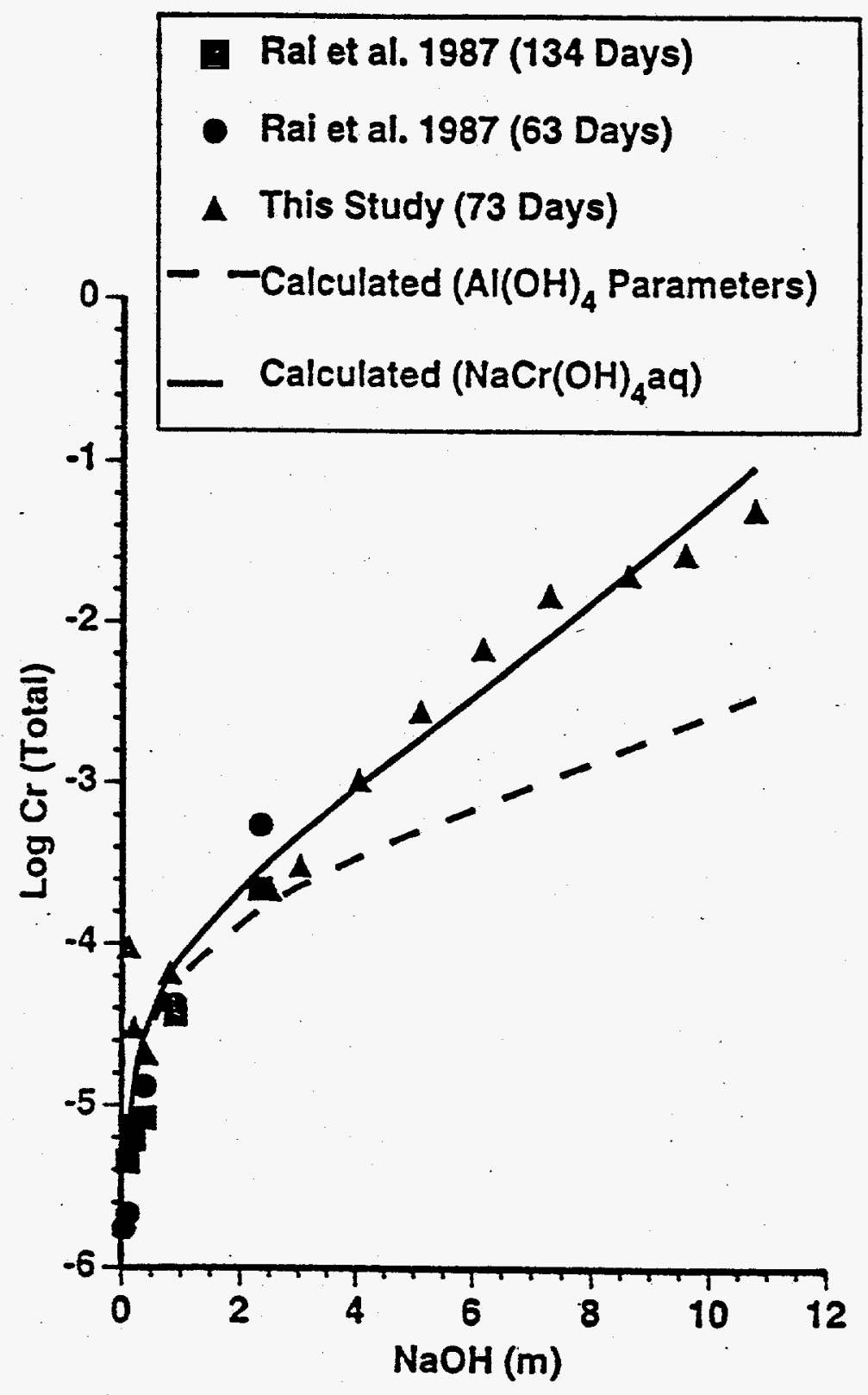

Figure 3. Calculated and experimental solubility data for $\mathrm{Cr}(\mathrm{OH})_{3}(\mathrm{am})$ in $\mathrm{NaOH}$. 
than $\mathrm{NaCrO}_{2}(\mathrm{c})$, indicating that structural units such as $\mathrm{Cr}(\mathrm{OH})_{5}{ }^{2-}$ or $\mathrm{Cr}(\mathrm{OH})_{6}{ }^{3-}$ are not important, at least in the solid phases. The only model that gave good overall agreement with the solubility data in $\mathrm{NaOH}$ (see solid line in Figure 3) and worked well when tested in the mixed $\mathrm{NaOH}-\mathrm{NaNO}_{3}$ system involved the introduction of a $\mathrm{NaCr}(\mathrm{OH})_{4}(\mathrm{aq})$ species. The standard chemical potential of this species was determined (fit) from the data in $\mathrm{NaOH}$ with the same model parameters for the $\mathrm{Cr}(\mathrm{OH})_{4}^{-}$as used to calculate the dashed line in Figure 3. The agreement between model and experiment for this model is quite good. In addition when this model is applied to the solubility data in the mixed $\mathrm{NaOH}-\mathrm{NaNO}_{3}$ system, the agreement between model and experiment is also quite good, with no model parameters adjusted (see Figure 4). This latter fact is especially important since it represents at least a partial validation of this thermodynamic model. The necessary model parameters for this thermodynamic model are summarized in Table 1.

In summary, the solubility of $\mathrm{Cr}(\mathrm{OH})_{3}(\mathrm{am})$ was studied in $\mathrm{NaOH}$ and mixed $\mathrm{NaOH}-$ $\mathrm{NaNO}_{3}$ solutions extending to high concentration. The results at lower $\mathrm{NaOH}$ (i.e., $<2.5 \mathrm{M}$ $\mathrm{NaOH})$ were consistent with previous investigators. A relatively simple thermodynamic model was developed which includes only two aqueous. Cr species and explains all of the solubility data for $\mathrm{Cr}(\mathrm{OH})_{3}(\mathrm{am})$ in both $\mathrm{NaOH}$ and $\mathrm{NaOH}-\mathrm{NaNO}_{3}$ solutions extending to very high electrolyte concentration.

Table 1. Parameters for the aqueous thermodynamic model.

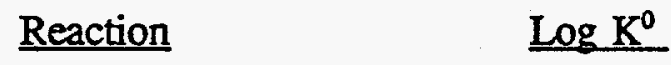

$\begin{array}{ll}\mathrm{Cr}(\mathrm{OH})_{3}(\mathrm{am})+\mathrm{OH}^{-}=\mathrm{Cr}(\mathrm{OH})_{4}^{-} & -18.30 \\ \mathrm{Na}^{+}+\mathrm{Cr}(\mathrm{OH})_{4}^{-}=\mathrm{NaCr}(\mathrm{OH})_{4}(\mathrm{aq}) & -0.052\end{array}$

Ion-Interaction Parameters(all $\mathrm{Al}(\mathrm{OH})_{4}{ }^{\circ}$ analogs)

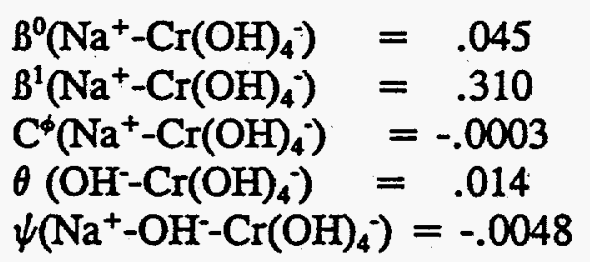




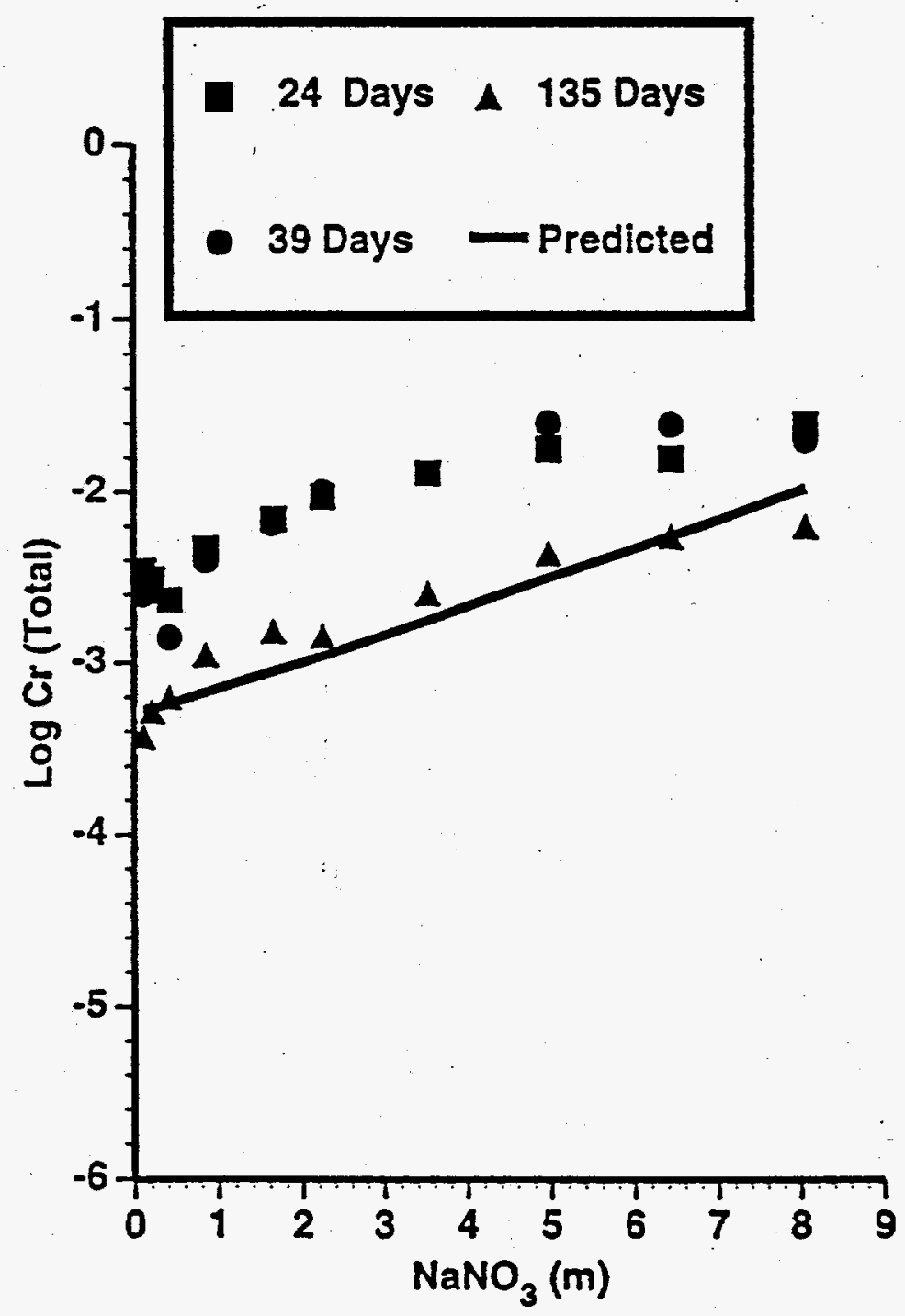

Figure 4. Solubility data for $\mathrm{Cr}(\mathrm{OH})_{3}(\mathrm{am})$ in mixed $\mathrm{NaOH}-\mathrm{NaNO}_{3}$ solutions. 


\section{References}

Pabalan R.T. and K.S. Pitzer (1987). Thermodynamics of $\mathrm{NaOH}(\mathrm{aq})$ in hydrothermal solutions. Geochimica et Cosmochima Acta: 51;829-837.

Rai D., B.M. Sass, and D.A. Moore. (1987). Chromium (III) hydrolysis constants and solubility of chromium (III) hydroxide. Inorganic Chemistry: 26;345-349.

Wesolowski D.J. (1992). Aluminum speciation and equilibria in aqueous solution: I. The solubility of gibbsite in the system $\mathrm{Na}-\mathrm{K}-\mathrm{Cl}-\mathrm{OH}-\mathrm{Al}(\mathrm{OH})_{4}$ from 0 to $100^{\circ} \mathrm{C}$. Geochimica et. Cosmochima Acta: 56;1065-1091.

WHC, (1993). Fate and Transport of Chromium in the Environment, WHC-SD-EN-ES-035, prepared by E. C. Thornton, Westinghouse Hanford Company, Richland, Washington. 